Cuadernos de Lingüística Hispánica $n^{\circ} .28$

ISSN 012 I-053X • ISSN en línea 2346- 1829

Julio-Diciembre 2016, pp. 115-126

\title{
La Estética del Lenguaje en la Obra Vallejiana*
}

JACQUELINE MURILLO GARNICA**
jmurillo55@hotmail.com

Recepción: 24 de enero de 2015

Aprobación: 16 de marzo de 2015

Forma de citar este artículo: Murillo Garnica, J. (2016). La Estética del Lenguaje en la Obra Vallejiana. Cuadernos de Lingüística Hispánica, (28), 115-126. doi: http://dx.doi.org/10.19053/0121053X.4911

* Artículo de reflexión.

** Investigadora literaria y docente universitaria. Doctora en Literatura Española e Hispanoamericana de la Universidad de Salamanca. Magíster en Literatura de la Pontificia Universidad Javeriana y Licenciada en Educación Básica Primaria de la misma universidad. 


\title{
Resumen
}

Este artículo escudriña en la estética del lenguaje del escritor Fernando Vallejo. Escarba en sus más recónditos y desaforados pensamientos, y los enlaza en la voz de su yo narrador; para entregarle al lector una larga y estimulada carga de sensaciones, con una desazón que salpica ese lenguaje sensible, vital, audaz y contundente en su obra. Su lenguaje categórico le advierte al lector el compromiso constante de su narrador con lo social, con la historia de su país, una voz que lo universaliza desde su preocupación por el existir.

Palabras clave: estética, lenguaje, sensibilidad y desazón.

\section{Aesthetics of Language in Vallejo's literary work}

\begin{abstract}
This article examines the aesthetics of language in the Colombian writer Fernando Vallejo. It explores this author's most hidden brutal thoughts, and links them together in the voice of the narrating "I", in order to give the reader a prolonged, stimulating emotional charge, with a turbulence that inevitably colors this sensitive vital, audatious, and aggressive literary work. His categorical language warns the reader of the narrator's constant commitment to social concerns and the history of his country, a universal voice born from his existential angst.
\end{abstract}

Key words: aesthetics, language, sensibility, turbulence 


\section{L'Esthétique du Langage dans l'Oeuvre Vallejiana}

\section{Résumé}

Cet article scrute dans l'esthétique du langage de l'écrivain Fernando Vallejo. Il fouille dans ses plus cachées et démesurées pensées, et les relit dans la voix de son « moi » narrateur, pour rendre au lecteur une longue et stimulée charge de sensations, avec une malaise qui parsème ce langage sensible, vital, audacieux et contondant dans son œuvre. Son langage catégorique remarque au lecteur le compromis constant de son narrateur avec le social, avec l'histoire de son pays; une voix que l'universalise depuis sa préoccupation pour l'exister.

Mots clés: esthétique, langage, sensibilité et malaise.

\section{A Estética da Linguagem na Obra Vallejiana}

\section{Resumo}

Este artigo esquadrinha na estética da linguagem do escritor Fernando Vallejo. Escarva em seus mais recônditos e desaforados pensamentos, e os enlaça na voz de seu eu narrador; para entregar-lhe ao leitor uma longa e estimulada carga de sensações, com uma inquietação que salpica essa linguagem sensível, vital, audaz e contundente em sua obra. Sua linguagem categórica adverte a leitor o compromisso constante de seu narrador com o social, com a história de seu país, uma voz que o universaliza desde sua preocupação pelo existir.

Palavras chave: estética, linguagem, sensibilidade e inquietação. 
«¿Qué es el hombre en la naturaleza?

Una nada frente al infinito,

un todo frente a la nada.

Un medio entre todo y nada».

Unamuno.

\section{Introducción}

Este documento explora el lenguaje y el discurso de Vallejo. Explica las palabras desde su significado, interpreta el sentido de su contexto, y juega con esa escritura paradojal del pensamiento humano: la envoltura y carne de una realidad que apalea las emociones, las sensaciones, lo visceral, lo racional e irracional.

La voz de Fernando Vallejo es una entidad que se compone y desvanece en medio de una geografía, de una conquista, de una estructura linguística que revela una observación envidiable, y autónoma de la realidad colombiana que se integra en nuestra sociedad. La focalización que realiza esta voz sobre la existencia del hombre le permite al lector deambular por las calles de la ciudad, de la infancia, del pensamiento, del sentir para aprehenderlo todo; desde la aridez de la vida que a veces lo consume, hasta la sórdida sonrisa que se permea entre las hermosas descripciones que solo la magia del lenguaje puede crear, recrear y transcrear.

Esta es la elección de Vallejo-autor porque él sin lugar a dudas, a diferencia de otros novelistas, escribe una verdad que mutila a Colombia, al hombre... sin escamotear en ocultar el desbarajuste, el tropel, el vacío, el abismo que circunda en nuestra vida. Vallejo no necesita sobre-adornar las palabras para llamar la atención del lector. Se podría decir que el placer de sus obras se contornea con cada expresión vulgar, cruda, parca, soez, fría; para él es una de las formas de discurso vigente en una sociedad también perturbada porque, aunque para mí resulte desafiante, lo cierto es que esa verdad impúdica vigoriza mi propia realidad.

Escritores como Vallejo logran destacarse dentro de la literatura colombiana, cuando a través de sus palabras, su pensamiento, sus obras, se muestra no solo como un creador que imagina diversas realidades para hablar de lo bello, de lo sutil, de lo sublime de las cosas, sino que se presenta dentro de una voz narradora, como un "simple" ser humano que no teme excluir nombres políticos, religiosos o familiares para exponer sus dudas, sus odios, sus aberraciones, sus conflictos internos. Los libros El desbarrancadero 
y El río del tiempo no conforman la historia de un Dios, ni la de un ser superior a los demás hombres, tampoco presentan la vida de un personaje de ficción a modo de modelo para imitar o de ejemplo a seguir, sino que a través del discurso narrativo, el autor expone la escabrosa vivencia de múltiples voces que se instauran a lo largo de la realidad a la que pertenece.

\section{El universo Vallejiano postula una estructura propia del lenguaje}

El ámbito de la referencia de las novelas de Vallejo, el giro inusual en las expresiones, el carácter contestatario, denunciante, la autorreferencialidad que expone, la endíadis de su discurso, la estética de la anacronía, el desmonte de lo verosímil, el mecanismo que utiliza para representar la omnipotencia del lenguaje, la relación que existe entre el lenguaje usado, la función narrativa y la intención significativa que le corresponde, se convierten en el sello que articula su diseño estético.

La voz de Fernando, esa que ama el lenguaje, esa voz que posee la habilidad para construir a partir del código linguístico una estética del lenguaje, puede llegar a destruir su propia configuración. Su voz, aferrada al fractal de la memoria del autor, busca retazos de episodios de la vida para decir sin ninguna pretensión, «Yo soy» ${ }^{1}$. El efecto que produce esa voz del narrador en el lector, es el desgarramiento de la palabra que lo imana hacia la narración misma para tratar de dar sentido a la odisea interna que allí se construye.

La impronta que deja la estética del lenguaje en el lector, dirige la voz del narrador, la vida de los personajes y el espacio sobre el principio de lo desmesurado y hasta cierto punto desolado. Esta voz crítica les permite, tanto al lector como a la misma voz, aventurarse en la espesura de lo incierto, en la densidad del alma, en la locura de la mente, en el raciocinio de las cosas. Son las preguntas internas de cualquier lector las que adquieren forma en el discurso del narrador; las que lo arrojan al artífice de la realidad produciendo el desvanecimiento físico de la palabra.

El siguiente pasaje, tal como lo describe la voz de Vallejo, sea cual seala representación de los antivalores que se circunscriben en la matriz de la realidad colombiana, logra concretar esa proliferación de episodios socio-políticos que coexisten en la memoria del lector para articular el holocausto que subyace en el ser humano:

1 Según Barthes (2006), en El grado cero de la escritura: "La lengua está más acá de la literatura. El estilo casi más allá: imágenes, elocución, léxico, nacen del cuerpo y del pasado del escritor y poco a poco se transforman en los automatismos de su arte. Así, bajo el nombre de estilo, se forma un lenguaje autárquico que se hunde en la mitología personal y secreta del autor, en esa hipofísica de la palabra donde se forma la primera pareja de las palabras y las cosas, donde se instalan de una vez por todas, los grandes temas verbales de su existencia" (p. 18). 
Saliendo del consulado colombiano en Roma, por el piazzale Flaminio, se me ocurrió la película. La vi completa, con sus decapitados, con sus incendios, con su rencor y su furia, con todo su horror, en un instante de iluminación o alucinación que abarcaba a Colombia. Veintinosecuantos años la llevé en el corazón hasta que pude filmar, por fin, en México, reconstruyendo a Colombia sobre el imposible, y nació como tenía que nacer, a medias y obsoleta, vieja (Vallejo, 1993, p. 577).

Así, no puede negarse que la voz del narrador se perfila en la medida en que cada palabra, cada expresión introduce al lector en un desbarrancadero que a su vez puede llegar a propiciar la subyugación de la mente. Tensión y sin sabor que se asumen desde lo abrupto del lenguaje y que, en forma consecuente, crean posiciones polivalentes hacia una realidad, al parecer, extrínseca, que se permea frente a una cruda existencia y que, a su vez, pone en evidencia la confusa y descabalada ánima del hombre contemporáneo.

Es claro que las novelas El río del tiempo y El desbarrancadero logran trasvasar la esencia de la libertad de la palabra, debido a la abundancia excesiva de revertimientos lógicos, a la estampida de enérgicos tropos literarios, y a los extraordinarios pasajes salpicados de humor e ironía; el lector, de manera indiscriminada, puede integrar cada juego de palabras en la metáfora de la existencia humana, una soterrada verdad que necesariamente se sostiene bajo la rúbrica de la voz narradora.

La estética de la desazón en el lenguaje de Vallejo no solo adiciona inestabilidad, aspiraciones frustradas, abyección, horror, fatalidad, melancolía, pasiones reprimidas sino que también induce al lector a tratar de adivinar en qué dirección se encamina esa voz, como un pasatiempo vano pero inevitable.

Esta concepción, basada en la funcionalidad estética, recreadora y formativa del lenguaje, le permite a la voz de Vallejo reírse de lo que ella narra con el desdén más tranquilo y pacífico que pueda esperarse. En consecuencia, el placer del texto se encuentra en el realce de esa voz narradora que impregna desazón y desconcierto a un lector que, en algunas ocasiones, calla aunque el silencio se convierta en una arma de doble filo en su conciencia.

El siguiente pasaje revela ese sinsabor que Vallejo despierta en los lectores, los más fieles seguidores de su discurso:

De la posteridad no esperes nada: unas flores, si acaso, en tu ataúd, con las paletadas de tierra en el entierro, y después polvo de olvido. Que hereden mierda (...) Oh Muerte justiciera, oh Muerte igualadora, comadre mía, mamacita, barre con esta partida de hijos de puta, no dejes uno, con tu aleteo bórralos a todos (Vallejo, 2001, p. 92). 
Variedad de ambigüedades argumentales y sicológicas, significados dobles y ausentes, juegos y rompecabezas, maraña y simplicidad, incongruencias y contradicciones se conjugan en el lenguaje para pluralizar la urdimbre que se teje a través de esa naturaleza híbrida y compleja que compone el claroscuro de su discurso. De este modo, "el autor se declara sujeto de su propio entendimiento (...), no es ante todo una situación o un hecho que pueda ser localizado en una historia, sino que es la manifestación, al nivel del referente, de una estructura linguística" (De Man, 1991, p. 114).

De ahí que este artículo se instaure, principalmente, sobre el principio de que los niveles lingüísticos que se manifiestan en las obras de Vallejo, están directamente vinculados con la multiplicidad de "realidades" bajo las cuales se configura una estética del lenguaje que se noveliza a partir de las múltiples situaciones y personajes evocados por la voz protagonista del relato.

Vallejo (1998), en el discurso de inauguración del Primer Congreso de Escritores Colombianos, ${ }^{2}$ hace una acotación refiriéndose a cómo debe ser la revelación total de nuestra actividad ante el existir, ante una realidad que al tiempo de influirnos como individuos, hace parte de una visión de colectividad que exige sin lugar a dudas un compromiso con la historia colombiana:

Que cada quien hable por sí mismo, en nombre propio, y diga lo que tenga que decir que el hombre nace solo y se muere solo y para eso estamos en Colombia donde por lo menos, en medio de este desastre, somos libres de irnos y volver cuando queramos, y de decir y escribir y opinar lo que queramos, así después nos maten (parr. 1).

El sentido de integración social que propugna Vallejo en su discurso es muy valioso, ya que promueve la consigna de una conciencia reflexiva, tal como se percibe en sus novelas El río del tiempo y El desbarrancadero. No cabe duda que la voz narradora de Vallejo agudiza las múltiples voces que han asistido a lo largo de la historia colombiana para invitar al lector a bucear por su mundo, su Colombia, su pensamiento, su más cercana y profana realidad.

Vallejo, no solo escavana, hurga, escoce en la conciencia del hombre colombiano para develar la primacía del «yo» literario; sino que también pone en concordancia mis aseveraciones y reafirmaciones con respecto a esa estética del lenguaje que se embiste de

2 Este discurso se encuentra como "Discurso del Congreso de Escritores Colombianos" en Peroratas (2013), sin embargo, también se encuentra en la revista Número con el título del "Monstruo Bicéfalo" (1998). 
riesgo, de rudeza, de desazón aunque con el permanente compromiso de autenticidad y proyección que marcan la tendencia y el criterio que presiden sus obras.

\section{El lenguaje como un vehículo de evocación}

La evocación es el recurso que usa Vallejo para manifestar el sentir de los personajes. Son los recuerdos de otros seres, vinculados directamente con el sentir de cada uno de los familiares, los que logran motivar la sensibilidad del lector. Es a partir del recuerdo del pasado que gira el discurso en la historia. Ese deseo nostálgico de Vallejo de recrear el pasado desencadena el placer de oír su propia voz en el presente. Es entonces cuando encontramos una excusa para las numerosas interrupciones y cambios de escenarios en el discurso, que caracterizan la mayoría de sus textos. Lo que es efímero a nivel narrativo es perenne con el entusiasmo del narrador al descubrir su propia voz, perecedera, falaz:

¡Bum! ¡Bum! ¡Bum! La cabeza del niño, mi cabeza, rebotaba contra el embaldosado duro y frío del patio, con la vasta tierra, el mundo, inmensa caja de resonancia de mi furia. ¿Tenía tres años? ¿Cuatro? No logro precisarlo. Lo que perdura en cambio, vívido, en mi recuerdo, es que el niño era yo, mi vago yo, fugaz fantasma que cruza de mi niñez a mi juventud, a mi vejez, camino de la muerte, y la dura frialdad del patio. (Vallejo, 1985, p. 26).

El idilio es la naturaleza y la infancia, recuerdos que a lo largo de la historia llegan a confundirse, en forma fragmentaria, como parte esencial del relato. La edad adulta es de inconformidad, rechazo y desprecio del presente. La memoria de Vallejo queda simbolizada en el fluir del río Cauca, que se muere y se refugia en la palabra:

¡Cuánto hace que el Cauca y el Magdalena se secaron, se murieron, los mataron con la tala de árboles y los borraron del mapa, como piensan que me van a borrar a mí pero se equivocan si los ríos pasan la palabra queda! (2010, p. 23).

El río representa la transformación del hombre, el continuo cambio, dos veces no nos bañamos en las aguas del mismo río: "(...) El río, si les digo la verdad y bien que lo conozco, se me hace triste y monótono, lento, fatigado, sin ganas de vivir, como si se arrastrase por la inercia de las edades sus cansadas aguas" (Vallejo, 2004, p. 7). Así, lo que refleja Vallejo es la contradicción del ser humano que repite sus mismos errores y cae en la decadencia, en la desesperanza, en la soledad y en la miseria.

La vida y la obra se unen en el momento en que la incomprensión del ser humano es el pan de cada día, y él advierte desde las críticas y su humor cáustico el aislamiento que recibe de ese mundo, instaurado por la política y la religión en un país de leguleyos y reproductores de una educación moralista, de solapados, del cual él se aleja y que le 
repugna, por ello su insistencia en los temas tratados en sus diferentes novelas. Insiste en lo rechazado, en lo que escandaliza y lo hace desde la crítica ácida y directa. Se pueden registrar los nombres y los estamentos que traen mayor escozor a la dirigencia de Colombia como epicentro de la sociedad mojigata y trasnochada en preceptos políticos y religiosos, y en un accionar salvaje e inhumano. Es por ello que ataca desde la misma postura, desde el mismo lenguaje descarnado que se ve en la sociedad; esto no significa que esté a la misma la altura de la delirante jerga humana vivida en las calles del país, sino que se apropia del mismo lenguaje para reducir desde la raíz y desde del origen, el salvaje mundo en que estamos inmersos en el día a día. Porque hablar desde la negación, argot descalificador y grotesco, le hace instaurar y avalar un lenguaje crítico, audaz y serio.

La precisión del lenguaje, las explicaciones a los términos usados y las autocorrecciones léxicas para enseñarle al lector, le permiten ahondar en el cuidado del uso del lenguaje y, a la vez, en que debemos estar atentos a nuestro modo de vivir y de morir. No podemos seguir viviendo en un mundo incivilizado que esté regido por los grandes jerarcas de la iglesia o la política, debido a ellos el país no surge y debido a la minoría en su actuar y en sus ganas de ser mayoría, se reduce el espacio de la vida digna. Es decir, el río está cada vez más sucio y alterado por la suciedad humana, en la que no podemos bañarnos.

La historia de su familia, narrada por él retrospectivamente, es simultánea al momento en que se está reconstruyendo. Se podría decir que el prolongado relato personal, del personaje narrador, es el medio que mantiene al lector en el curso de las situaciones que se narran en la novela. El lector tiene que esforzarse para eslabonar las piezas que se conectan, aparte de que se compromete a construir los hechos y las identidades que se asoman en la estructura de un relato. Es como si el narrador quisiera que fuéramos testigos de sus profundos secretos:

Cierro los ojos y vuelvo, con la imaginación del recuerdo, a esa calle del Ricaurte, a mezclarme con los transeúntes de la hora, a mirar al niño vestido de rojo en su ventana. Y se esboza una tenue sonrisa en mi memoria por lo que el niño hace (...) Ya no existe la calle de Ricaurte, ya no existe la casa, ya no existe la reja, ya no existe la ventana. Como a todo en Medellín se lo llevó el ensanche. Que se lleve el ensanche mi recuerdo. (Vallejo, 1985, p. 32).

Por esta razón, el lector, al igual que Vallejo, vaga con incertidumbre por los oscuros rincones de la casa, siguiendo los pasos de Fernando y su familia. El paisa, en El Desbarrancadero, no solo dibuja con palabras una imagen descarnada y oscura de la vida moderna sino que retrata las consecuencias de la violencia que ha vivido o ha tenido que soportar el país en medio de una crisis integral, que se lleva solo a unos pocos a la 
desgracia. Además, ataca en forma satírica la enfermedad de su hermano Darío como si fuese el pretexto que le permitiera dirigirse en contra de una sociedad que aún no se ha atrevido a hablar abiertamente sobre la enfermedad del sida. ${ }^{3}$

Fernando es el cronista de un mundo que muere, que agoniza como Darío, como su padre, y donde la única señal es la perpetuidad del recuerdo. Ante esa vida que no puede salvar, el narrador revela la condición moral del sobreviviente: el testigo de la muerte es un cadáver que recuerda. En esa vía, la inclusión de un lector explícito en la obra subraya el estatus ficticio del discurso (Tittler, 1990), pues la voz narrativa sabe que existe solamente en lo impreso y constituye un intento para establecer el nexo entre los mundos textuales y extratextuales.

Así, la estética de la desazón en el lenguaje de Vallejo cobra vida en el tránsito del uso de cada palabra. Se podría decir que el estilo de la línea linguística que propone el autor, a la vez que devela una conducta humana-salvaje, es visionaria de una "verdad heredada, recitativa, contemplativa, parasitaria" que compromete al lector; lo seduce al misterio de socavar uno a uno los intereses, los pensamientos, los sentimientos, las sensaciones de una parafernalia escondida, ignorada, mecanizada.

No cabe duda que Vallejo utiliza el lenguaje como una de las acciones narrativas de enlace estructural en sus novelas, como su ardid más eficaz para combatir la abyección de la realidad. Los juegos lingüísticos muestran la arbitrariedad del signo, multiplican los sentidos, llaman la atención del lector sobre la dimensión significante de la lengua. Con Vallejo, el lenguaje se convierte en el poder que incita al lector, a los mismos personajes de la historia a gritar, apuñalar, disparar, "enrevesar", "argamasar" todo tipo de emociones y reacciones.

\section{Conclusiones}

No hay que olvidar que las obras de Vallejo están subordinadas a su voz protagonista y de él a su vez. Por supuesto, de esta conexión, depende el encuentro consigo mismo, con su propia vida, con nuestra propia realidad. Además, la voz irónica a través de la cual el

3 "El amor homosexual ha sido un tópico difícil para la literatura hispanoamericana contemporánea, principalmente por la impericia de los autores al tratar el tema... La mayoría se conforma con un erotismo repetitivo y solemne, o bien una farsa melodramática que, a estas alturas, ya ni siquiera nos hace sonreir. Fernando Vallejo evita ambos escollos obrando con eminencia intelectual: su novela no es erótica sino tanática. Su campo de batalla es la mente, no la piel... Por lo que atañe a las probables escenas de erotismo homosexual, éstas han sido suprimidas sistemáticamente, como si el narrador no quisiera que su presencia negara 0 atemperara la perspectiva de que el mundo... fue y será una porquería. De tal suerte, la homosexualidad aparece en La virgen de los sicarios como una actitud moral de los personajes. También como un recurso estilístico, un potente catalizador de la misantropía y el horror ante la capacidad de engendrar" (Herbert, 2001, citado por Crespo, 2003, párr. 40). 
autor ha elegido hablar, es un tipo de mediatriz que articula o desarticula la comunicación con el lector.

Cabe resaltar que, a partir del encuentro de múltiples formas de lenguaje social, que provienen de los diferentes estratos del medio urbano, el lector se ve inmerso casi sin notarlo en una postura dinámica en la que la polivalencia del lenguaje, su ambigiedad, su referencialidad, su valor icónico, su significado lo comprometen a vivir las experiencias del personaje protagonista.

La estética de la desazón en el lenguaje de Vallejo constituye el reto de la escritura, pues no solo da cuenta de una época que se perfila neurótica, catártica, misteriosa sino que involucra una vía de acceso hacia los misterios de la catéresis. Tal como se presenta en nuestra cotidianidad, el lenguaje toca la condición del hombre en lo más profundo, como si las catacumbas de nuestra alma provocaran en el lector una autarquía que se consolida bajo los escombros de la desazón.

La estética que devana Vallejo a partir de sus obras representa la crítica de la realidad que se percibe, que se deforma como resultante de un mundo desestructurado, libre de recepciones y emisiones racionales ordenadas. Al parecer, la desinhibición de sus palabras se convierte en el arma linguística más poderosa para plantear desde la evocación de su realidad, el realce de una literatura dietética, de una voz narradora que se afirma mediante la negación de la sociedad, del tiempo, del espacio, de la marginalidad en que fue incluido.

De otro lado, nos induce a la exaltación, a la transcreación, a la paráfrasis del lenguaje, confundiendo la vasta llanura de la realidad que atrapa al hombre con la fantasía, el juego creativo de la imaginación. El lenguaje confesional, intimista que emplea Vallejo constata el carácter magistral de sus obras; no solo ilumina el código de la escritura desde la contemplación de lo real, sino que nos confirma que el lenguaje es el complejo que persigue la liberación del yo como vehículo anverso de una realidad imprevisible, deconstructiva. Al parecer, la voz narradora de Vallejo se vuelca sobre sí misma postulando una escritura de la ontología, en donde se revierte la imprecación de la palabra.

Barthes (1974) se refiere al texto como un producto que "se trabaja a través de un entrelazado perpetuo; perdido en ese tejido -esa textura- el sujeto se deshace en él como una araña que se disuelve en las segregaciones constructivas de su tela" (p. 104). De ahí, el talante de la estética de Vallejo, un discurso narrativo, una estructura compleja que se multiplica en la reiteración de evocaciones que convergen en espacios urbanos, rurales, familiares; cuadros que viajan desde el pasado para alojarse en un presente quebrantado, sensaciones recuperadas; secuelas que se rastrean en un incesante ir y venir de la infancia a la edad adulta y viceversa. 
Testimonios, percepciones, vivencias personales de hechos políticos, sociales, culturales que estigmatizan la sociedad colombiana; redes analógicas que acentúan lo obvio y lo incomprensible; perversidades sexuales que modifican la constitución afectiva y psíquica del protagonista; episodios violentos que componen una masa popular desorientada y amorfa; inserción de voces anónimas que nutren una realidad patética y amarga; viajes interiores en busca de un yo cada vez más enmarañado por el sinsabor de la vida conforman esa gama de imágenes superpuestas, esa cárcel que enlaza la múltiple y dispersa la realidad de la palabra escrita en el engranaje de una estética que provoca, sacude y cimbronea al lector.

\section{Referencias bibliográficas}

Barthes, R. (1974). El placer del texto. México: Editorial Siglo XXI.

Barthes, R. (2006). El grado cero de la escritura. México: Editorial Siglo XXI.

Crespo, E. (2003) La virgen de los sicarios como extensión de la narrativa de la transculturación. Espéculo, (24). Recuperado de https://pendientedemigracion.ucm.es/info/especulo/ numero24/virgen.html

De Man, P. (1991). La autobiografía como des-figuración. Suplemento Anthropos, (29), 113-118.

Tittler, J. (1990) Ironía narrativa en la novela bispanoamericana contemporánea. Colección bibliográfica. Bogotá: Banco de la República. 287.

Vallejo, F. (2004). Mi hermano el alcalde. México: Alfaguara.

Vallejo, F. (2001). El desbarrancadero. México: Alfaguara.

Vallejo, F. (1998). El monstruo bicéfalo. Revista Número, (20). Recuperado de http://www. revistanumero.com/20bicefala.htm

Vallejo, F. (1993). Entre fantasmas. En El río del tiempo. México: Alfaguara.

Vallejo, F. (1985). Los días azules. En El río del tiempo. México: Alfaguara. 